\title{
RNAseq analysis of hippocampal microglia after kainic acid-induced seizures
}

\author{
Dale B. Bosco ${ }^{1}$, Jiaying Zheng ${ }^{1}$, Zhiyan X $\mathbf{u}^{2}$, Jiyun Peng ${ }^{1}$, Ukpong B. Eyo ${ }^{1}, \mathrm{Ke} \mathrm{Tang}^{3}$, Cheng Yan ${ }^{3}$, Jun Huang ${ }^{3}$, \\ Lijie Feng ${ }^{4}$, Gongxiong Wu ${ }^{5}$, Jason R. Richardson ${ }^{6}$, Hui Wang ${ }^{2,7^{*}}$ and Long-Jun $\mathrm{Wu}^{1,8^{*}}$ (D)
}

\begin{abstract}
Microglia have been shown to be of critical importance to the progression of temporal lobe epilepsy. However, the broad transcriptional changes that these cells undergo following seizure induction is not well understood. As such, we utilized RNAseq analysis upon microglia isolated from the hippocampus to determine expression pattern alterations following kainic acid induced seizure. We determined that microglia undergo dramatic changes to their expression patterns, particularly with regard to mitochondrial activity and metabolism. We also observed that microglia initiate immunological activity, specifically increasing interferon beta responsiveness. Our results provide novel insights into microglia transcriptional regulation following acute seizures and suggest potential therapeutic targets specifically in microglia for the treatment of seizures and epilepsy.
\end{abstract}

\section{Introduction}

Temporal lobe epilepsy (TLE) represents the most common form of focal epileptic disorder. While several pharmaceutical treatments are currently available to mitigate and reduce seizure occurrence, as many as one third of patients display resistance to medication [1]. As such, an unmet need exists, requiring further investigation into the mechanisms underlying TLE. The rodent kainic acid (KA) epilepsy model can recapitulate many of the physical features of TLE including behavioral seizures and neuropathological lesions [2]. Therefore, many investigations have focused on how KA alters the activity and viability of neurons. However, comparatively little attention has been paid to glial cells, including astrocytes and microglia, in epileptogenesis [3, 4].

Comprising between 5 and $15 \%$ of total central nervous system (CNS) cells, microglia predominantly serve as the resident immune cell of the CNS. Recent evidence has also revealed that microglia have a diverse set of roles within the CNS, including directing neuronal maturation and supporting synaptic turnover $[5,6]$. With regard to epilepsy, it was established relatively early that

\footnotetext{
* Correspondence: huiwangph@ntu.edu.cn; wu.longjun@mayo.edu 2Department of Pharmacology, School of Pharmacy, Nantong University, 19 Qixiu Road, Nantong 226001, Jiangsu, China

1 Department of Neurology, Mayo Clinic, 200 First Street SW, Rochester, MN 55905, USA

Full list of author information is available at the end of the article
}

large numbers of reactive microglia can be found within the hippocampus of temporal lobe epilepsy patients $[7,8]$. Our recent studies demonstrated that seizures can acutely induce microglia-neuron interaction as well as the changes in microglial landscape [9-12]. Microgliosis and inflammatory cytokine release has been observed within areas of neuronal damage implicating microglia in promotion of neuropathy [13]. However, microglia may also have neuroprotective roles such as modulating excitotoxicity.

Since microglia seem to be an important part of the epileptic response, we investigated how KA-induced seizures modulate microglial transcriptional activity and alters their phenotype. Specifically, we investigated hippocampal microglia since this brain region is one of the most affected by seizure [14]. To explore this, we performed RNAseq analysis, a powerful tool to determine wide scale phenotypic alterations, on isolated hippocampal microglia from mice that received KA. We report that KA-induced seizures resulted in significant transcriptional changes to microglia when compared to sham controls. Specifically, there are significant increases in the expression of metabolic and mitochondrial pathways. Coincidently, we observed that immune related factors were also being up-regulated, including several chemokine factors such as chemokine ligand 5 (CCL5) and $\mathrm{C}-\mathrm{X}-\mathrm{C}$ motif chemokine 10 (CXCL10). We also

(C) The Author(s). 2018 Open Access This article is distributed under the terms of the Creative Commons Attribution 4.0 International License (http://creativecommons.org/licenses/by/4.0/), which permits unrestricted use, distribution, and reproduction in any medium, provided you give appropriate credit to the original author(s) and the source, provide a link to the Creative Commons license, and indicate if changes were made. The Creative Commons Public Domain Dedication waiver (http://creativecommons.org/publicdomain/zero/1.0/) applies to the data made available in this article, unless otherwise stated. 
observed that microglia increased their responsiveness to interferon $\beta$, possibly through interferon regulatory factor 7 (Irf7). Thus, we show that KA-induced seizures significantly regulate the microglia transcriptome, providing novel directions for further investigation.

\section{Results}

Kainic acid induced seizures significantly alters microglial gene expression profile

To begin our investigation, heterozygote $\mathrm{CX} 3 \mathrm{CR} 1^{\mathrm{GFP} /+}$ mice were treated with kainic acid (KA) via ICV injection to induce an acute seizure response [12]. Microglia in the mouse hippocampus show dramatic reactivity following KA-induced seizure strating at as early as 1 day and peaks at 3 days after KA treatment [15]. We therefore focused on hippocampus microglia isolated via FACS 3 days after KA-induced seizures. RNAseq libraries were constructed using the isolated cells and loaded onto an Illumina Hiseq platform. DEseq was used to determine differential gene expression. From the results, over 2300 differentially expressed genes were identified (Fig. 1a, Additional file 1: Table S1). Of these, we observed many of the suggested microglia specific genes including P2Y12, Tmem119, and Olfml3 [16]. Additionally, we detected only slight increases to myelin (e.g., PLP), neuronal (e.g., Rbfox3, Map2), and astrocytes (e.g.,
Gfap, Aldh1l1) markers within samples isolated from KA treated mice, with only GFAP registering as significant. These factors were not detected within the control samples. Since it has been suggested that the phagocytic capacity of microglia is substantially reduced following KA-seizure [17] and that microglial could express GFAP [18] we believe that the genes alterations that were deemed significant reflect microglia specific alterations. These results demonstrated the purity of microglia sorting. The overwhelming majority of differentially expressed genes were up-regulated in the microglia samples from KA treated mice with few genes being down-regulated when compared to sham controls (Fig. 1b-c). Table 1 lists the top 25 up-regulated and Table 2 the identified down-regulated genes. Table 3 lists the top 25 genes found only in the KA-treated animals as determined by $\mathrm{P}_{\text {adj }}$ values.

We next determined whether KA-induced seizures affected microglial specific markers. Using the list determined by Hickman et al. [16], we found that seven of the listed microglial markers were differentially expressed (Fig. 2a, Additional file 2: Figure S1). These were adenosine A3 receptor (Adora 3), crystallin beta A4 (Cryba4), galactose-3-O-sulfotransferase 4 (Gal3st4), lipase member $\mathrm{H}$ (Liph), membrane-spanning 4-domains, subfamily A, member 6B (Ms4a6b), serine peptidase
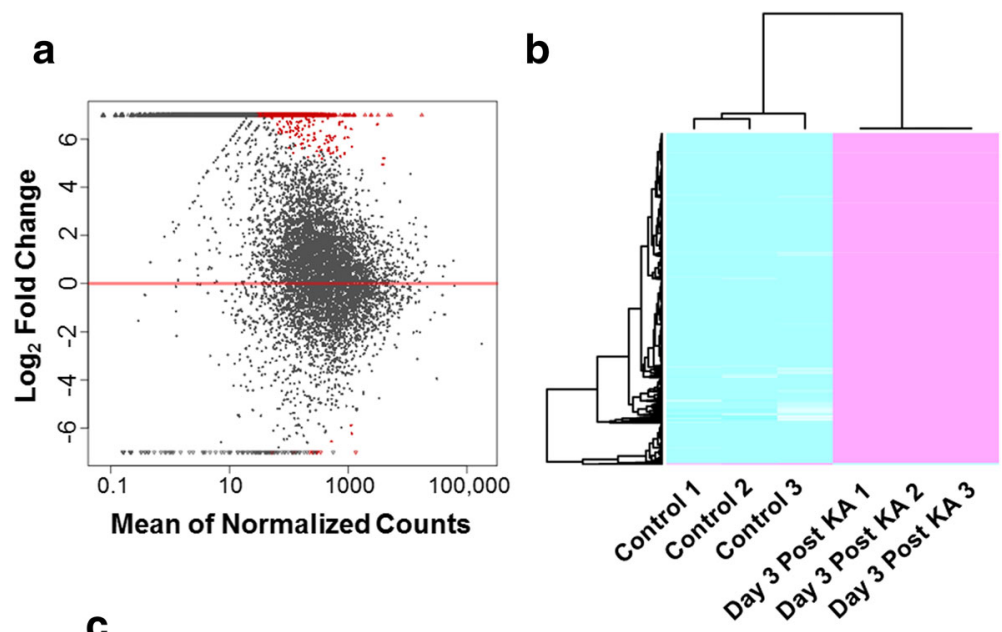

C

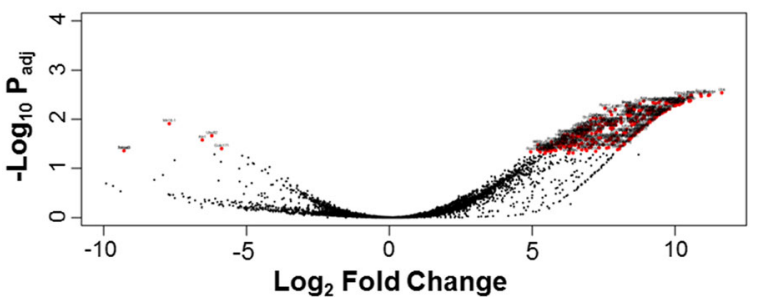

Fig. 1 Differentially expressed genes between the sham control and KA treated groups. a MA-plot of gene expression. All significant differentially expressed genes $\left(P_{a d j}<0.05\right)$ and locally weighted smoothing (LOESS) line are colored in red. $\mathbf{b}$ Heat map and hierarchical clustering was performed based on all differentially expressed genes. Magenta indicates high relative expression, and cyan indicates low relative expression. c Volcano plot of gene expression. All significant differentially expressed genes are colored in red and labeled by gene symbols 
Table 1 Top 25 most up-regulated genes

\begin{tabular}{|c|c|c|c|c|c|}
\hline ENSEMBL & Gene ID & Gene Symbol & Gene Name & $\log _{2}$ Fold Change & $P_{\text {adj }}$ \\
\hline ENSMUSG00000019505 & 22187 & Ubb & ubiquitin B(Ubb) & 11.64 & $2.89 \mathrm{E}-03$ \\
\hline ENSMUSG00000006418 & 81018 & Rnf114 & ring finger protein 114(Rnf114) & 11.21 & $3.18 \mathrm{E}-03$ \\
\hline ENSMUSG00000005881 & 66366 & Ergic3 & ERGIC and golgi 3(Ergic3) & 11.17 & 3.27E-03 \\
\hline ENSMUSG00000090841 & 17904 & Myl6 & $\begin{array}{l}\text { myosin, light polypeptide } 6 \text {, alkali, } \\
\text { smooth muscle and non- muscle(Myl6) }\end{array}$ & 10.91 & 3.39E-03 \\
\hline ENSMUSG00000040952 & 20085 & Rps19 & ribosomal protein S19(Rps19) & 10.90 & 3.07E-03 \\
\hline ENSMUSG00000042650 & 268420 & Alkbh5 & alkB homolog 5, RNA demethylase(Alkbh5) & 10.58 & 3.27E-03 \\
\hline ENSMUSG00000047215 & 20005 & Rpl9 & ribosomal protein L9(Rp|9) & 10.54 & 3.27E-03 \\
\hline ENSMUSG00000020664 & 13382 & Dld & $\begin{array}{l}\text { dihydrolipoamide } \\
\text { dehydrogenase(Dld) }\end{array}$ & 10.54 & 4.14E-03 \\
\hline ENSMUSG00000025959 & 93691 & Klf7 & Kruppel-like factor 7 (ubiquitous)(Klf7) & 10.52 & $4.28 \mathrm{E}-03$ \\
\hline ENSMUSG00000022982 & 20655 & Sod1 & superoxide dismutase 1 , soluble(Sod1) & 10.51 & 4.21E-03 \\
\hline ENSMUSG00000026213 & 71728 & Stk11ip & $\begin{array}{l}\text { serine/threonine kinase } 11 \text { interacting } \\
\text { protein(Stk11ip) }\end{array}$ & 10.49 & 4.28E-03 \\
\hline ENSMUSG00000031483 & 244373 & Erlin2 & ER lipid raft associated 2(Erlin2) & 10.45 & $3.66 \mathrm{E}-03$ \\
\hline ENSMUSG00000029298 & 236573 & Gbp9 & guanylate-binding protein 9(Gbp9) & 10.27 & 4.58E-03 \\
\hline ENSMUSG00000034855 & 15945 & Cxcl 10 & chemokine (C-X-C motif) ligand 10(Cxcl10) & 10.27 & $3.78 \mathrm{E}-03$ \\
\hline ENSMUSG00000070031 & 434484 & Sp140 & Sp140 nuclear body protein(Sp140) & 10.24 & 4.59E-03 \\
\hline ENSMUSG00000054920 & 71778 & Klhl5 & kelch-like 5(K|h|5) & 10.22 & 4.74E-03 \\
\hline ENSMUSG00000040447 & 216892 & Spns2 & spinster homolog 2(Spns2) & 10.17 & 4.91E-03 \\
\hline ENSMUSG00000022884 & 13682 & Eif4a2 & eukaryotic translation initiation factor 4A2(Eif4a2) & 10.16 & $3.39 \mathrm{E}-03$ \\
\hline ENSMUSG00000028962 & 20535 & Slc4a2 & $\begin{array}{l}\text { solute carrier family } 4 \text { (anion exchanger), } \\
\text { member 2(SIc4a2) }\end{array}$ & 10.15 & 4.93E-03 \\
\hline ENSMUSG00000047153 & 219094 & Khnyn & $\mathrm{KH}$ and NYN domain containing(Khnyn) & 10.15 & 5.07E-03 \\
\hline ENSMUSG00000030298 & 110379 & $\operatorname{Sec} 13$ & $\begin{array}{l}\text { SEC13 homolog, nuclear pore and COPII coat } \\
\text { complex component(Sec13) }\end{array}$ & 10.12 & $4.98 \mathrm{E}-03$ \\
\hline ENSMUSG00000031378 & 11666 & Abcd 1 & $\begin{array}{l}\text { ATP-binding cassette, sub-family D (ALD), } \\
\text { member } 1 \text { (Abcd1) }\end{array}$ & 10.11 & $4.28 \mathrm{E}-03$ \\
\hline ENSMUSG00000004568 & 102098 & Arhgef18 & $\begin{array}{l}\text { rho/rac guanine nucleotide exchange factor } \\
\text { (GEF) 18(Arhgef18) }\end{array}$ & 10.02 & 5.27E-03 \\
\hline ENSMUSG00000030577 & 12483 & $\mathrm{Cd} 22$ & CD22 antigen(Cd22) & 10.02 & $5.22 \mathrm{E}-03$ \\
\hline ENSMUSG00000031858 & 74549 & Mau2 & MAU2 sister chromatid cohesion factor(Mau2) & 10.01 & 4.58E-03 \\
\hline
\end{tabular}

Table 2 Down-regulated genes

\begin{tabular}{|c|c|c|c|c|c|}
\hline ENSEMBL & Gene ID & Gene Symbol & Gene Name & $\log _{2}$ Fold Change & $P_{\text {adj }}$ \\
\hline ENSMUSG00000000562 & 11542 & Ccdc171 & adenosine A3 receptor(Adora3) & -5.87 & $3.98 \mathrm{E}-02$ \\
\hline ENSMUSG00000090137 & 22186 & Uba52 & $\begin{array}{l}\text { ubiquitin A-52 residue ribosomal protein } \\
\text { fusion product } 1 \text { (Uba52) }\end{array}$ & -6.22 & 2.17E-02 \\
\hline ENSMUSG00000052407 & 320226 & Atn1 & coiled-coil domain containing $171(\mathrm{Ccdc} 171)$ & -6.55 & 2.65E-02 \\
\hline ENSMUSG00000092995 & 387134 & Mir16-1 & microRNA 16-1(Mir16-1) & -7.71 & $1.23 \mathrm{E}-02$ \\
\hline ENSMUSG00000004263 & 13498 & Adora3 & atrophin 1(Atn1) & -9.29 & 4.39E-02 \\
\hline ENSMUSG00000074344 & 69296 & Tmigd3 & $\begin{array}{l}\text { transmembrane and immunoglobulin } \\
\text { domain containing } 3(T m i g d 3)\end{array}$ & -9.29 & 4.39E-02 \\
\hline
\end{tabular}


Table 3 Top 25 differentially expressed genes only observed in KA treated group

\begin{tabular}{|c|c|c|c|c|}
\hline ENSEMBL & Gene ID & Gene Symbol & Gene Name & $P_{\text {adj }}$ \\
\hline ENSMUSG00000069516 & 17105 & Lyz2 & lysozyme 2 & $6.62 \mathrm{E}-04$ \\
\hline ENSMUSG00000060938 & 19941 & Rpl26 & ribosomal protein L26 & 1.15E-03 \\
\hline ENSMUSG00000002602 & 26362 & Axl & AXL receptor tyrosine kinase & 2.25E-03 \\
\hline ENSMUSG00000031320 & 20102 & $\operatorname{Rps} 4 x$ & ribosomal protein S4, X-linked & 2.25E-03 \\
\hline ENSMUSG00000049313 & 20660 & Sorl 1 & sortilin-related receptor, LDLR class A repeats-containing & 2.25E-03 \\
\hline ENSMUSG00000062006 & 68436 & Rpl34 & ribosomal protein $\mathrm{L} 34$ & 2.25E-03 \\
\hline ENSMUSG00000063524 & 619547 & Rpl34-ps1 & ribosomal protein L34, pseudogene 1 & 2.25E-03 \\
\hline ENSMUSG00000069516 & 100043876 & Gm4705 & predicted gene 4705 & 2.25E-03 \\
\hline ENSMUSG00000063524 & 13806 & Eno1 & enolase 1, alpha non-neuron & 2.25E-03 \\
\hline ENSMUSG00000069892 & 245240 & $9,930,111$ J21 Rik2 & RIKEN cDNA 9,930,111 J21 gene 2 & 2.25E-03 \\
\hline ENSMUSG00000089809 & 319818 & A930011G23Rik & RIKEN cDNA A930011G23 gene & $2.25 \mathrm{E}-03$ \\
\hline ENSMUSG00000090733 & 57294 & Rps27 & ribosomal protein $\$ 27$ & 2.25E-03 \\
\hline ENSMUSG00000073418 & 12268 & $c 4 b$ & complement component 4B & 2.83E-03 \\
\hline ENSMUSG00000001794 & 12336 & Capns1 & calpain, small subunit 1 & 2.94E-03 \\
\hline ENSMUSG00000003518 & 72349 & Dusp3 & dual specificity phosphatase 3 & 2.94E-03 \\
\hline ENSMUSG00000005566 & 21849 & Trim28 & tripartite motif-containing 28 & 2.94E-03 \\
\hline ENSMUSG00000009687 & 18301 & Fxyd5 & FXYD domain-containing ion transport regulator 5 & 2.94E-03 \\
\hline ENSMUSG00000022415 & 20972 & Syngr1 & synaptogyrin 1 & 2.94E-03 \\
\hline ENSMUSG00000022477 & 11429 & Aco2 & aconitase 2 , mitochondrial & 2.94E-03 \\
\hline ENSMUSG00000022565 & 18810 & Plec & plectin & 2.94E-03 \\
\hline ENSMUSG00000024679 & 68774 & Ms4a6d & membrane-spanning 4-domains, subfamily A, member 6D & 2.94E-03 \\
\hline ENSMUSG00000025498 & 54123 & Irf7 & interferon regulatory factor 7 & 2.94E-03 \\
\hline ENSMUSG00000026222 & 20684 & Sp100 & nuclear antigen Sp100 & 2.94E-03 \\
\hline ENSMUSG00000026430 & 54354 & Rassf5 & Ras association (RalGDS/AF-6) domain family member 5 & 2.94E-03 \\
\hline ENSMUSG00000034854 & 73822 & Mfsd12 & major facilitator superfamily domain containing 12 & 2.94E-03 \\
\hline
\end{tabular}

inhibitor Kunitz type 1 (Spint1), and toll-like receptor 12 (Tlr12). Since KA treatment has also been shown to induce inflammatory responses [15], we also investigated our list of differentially expressed genes for potential inflammatory markers. Indeed, we found a number of inflammatory factors are increased within microglia isolated from $\mathrm{KA}$ treated mice, including $\mathrm{C}-\mathrm{C}$ motif chemokine ligand 5 (Ccl5), $\mathrm{Ccl} 7$, and C-X-C motif chemokine ligand 10 (Cxcl10) (Fig. 2b, Additional file 2: Figure S2). We determined that expression of several inflammatory and immunological response receptors are also increased (Fig. 2c). These receptors included $\mathrm{C}-\mathrm{C}$ motif chemokine receptor 2 (Ccr2), C-X-C motif chemokine receptor 4 (Cxcr4), and Tlr1. Finally, a significant number cluster of differentiation (CD) markers were significantly increased (Fig. 2d). The majority of identified CD markers are related to immunological responses including $\mathrm{CD} 40$, CD69, and CD80 $[19,20]$. These results suggest that microglia are undergoing immunological activation in response to KA-induced seizures.

\section{Gene ontology analysis indicates significant increases to metabolic processes}

Our next step was to identify if any unifying features existed within our differential expression data set. As such, we utilized clusterProfiler to perform gene ontology (GO) analysis [21]. We investigated our data set using the three major classifications, cellular component, biological process, and molecular function (Additional file 3: Table S2, Additional file 4: Table S3 and Additional file 5: Table S4). To further visualize our results, identified $\mathrm{GO}$ terms were input into REViGO [22]. This web-based application allows for long lists of GO terms to be summarized and grouped based on semantic similarities. REViGO analysis was run using the associated $\mathrm{P}_{\text {adj }}$ for each identified GO term, with medium allowed similarity (0.7), and SimRel similarity measurement. TreeMaps were then generated for each ontology classification. Each box represents GO terms that are then grouped and colored based on keyword similarities. Box size indicates each terms level of significance as determined by input $\mathrm{P}_{\text {adj }}$ values. Added labels highlight overarching grouping terms. As Fig. 3a illustrates there are significant alterations 


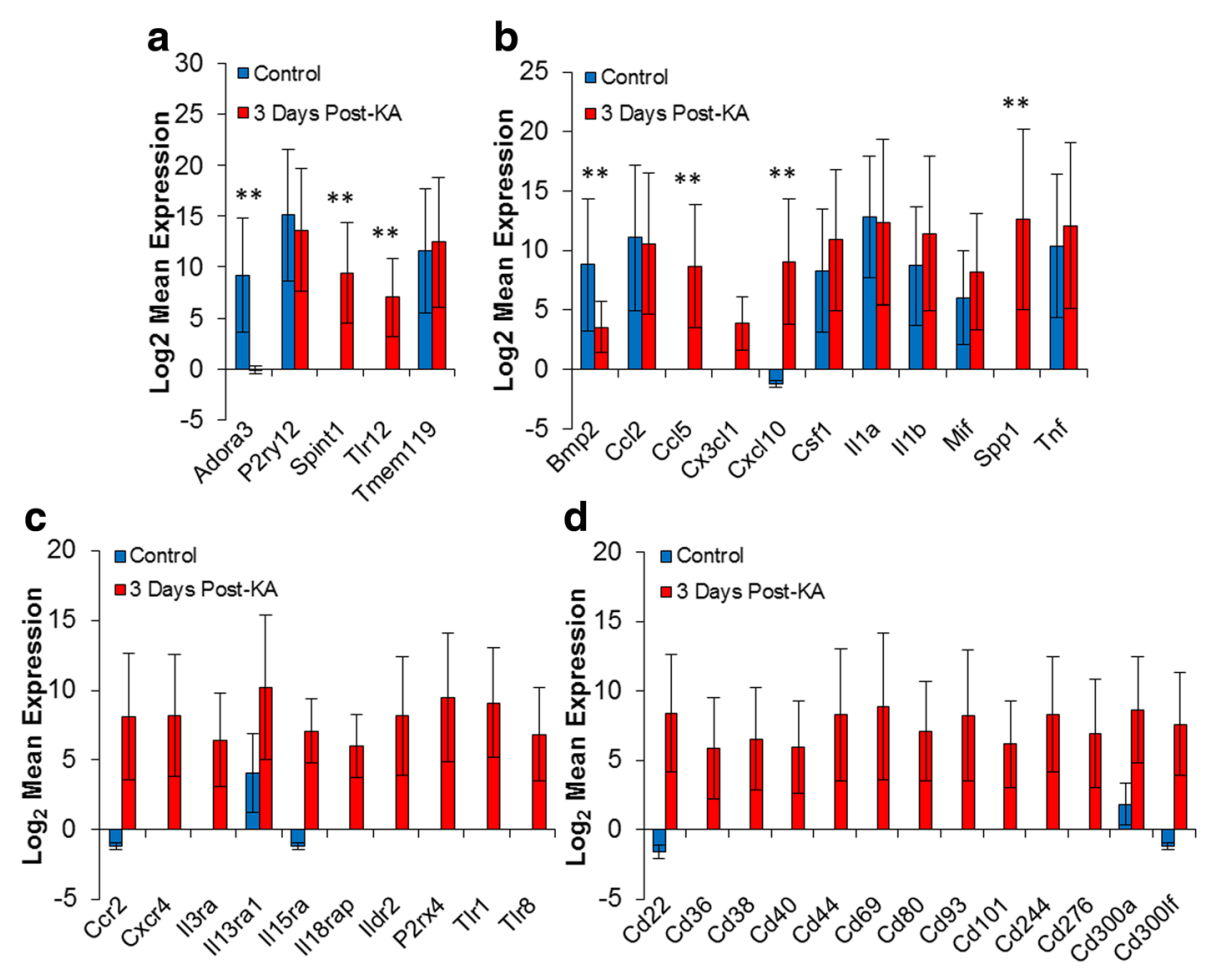

Fig. 2 Selected differential expressed genes. Expression results were investigated for genes relating to microglial specificity and inflammatory and immunological regulation. a Microglial markers. b Secreted factors. c Related receptors. d CD markers. Values are expressed and mean \pm standard error. ${ }^{*} \mathrm{P}_{\mathrm{adj}}<0.05$. All gene listed in panel $(\mathbf{c}$ and $\mathbf{d})$ had a $\mathrm{P}_{\mathrm{adj}}<0.05$

to intracellular factor expression, especially within the mitochondria. Moreover, Biological process GO analysis showed that there seems to be significant alterations to microglial metabolism, with catabolism being at the forefront (Fig. 3b). It also identified that microglia were activating viral defense mechanisms following seizure. Finally, we observed that a number of transferase activities were being undertaken following seizure (Fig. 3c).

\section{Kainic acid treatment may sensitize microglia to interferon beta}

Delving deeper into the identified GO terms it was observed that a number of related terms were pertinent to type I interferons, specifically interferon $\beta$ $($ IFN- $\beta$ ). Table 4 summarizes these identified GO terms. IFN $-\beta$ is a type-I interferon that binds interferon- $\alpha / \beta$ receptor (IFNAR) to regulate a multitude of signaling cascades particularly the JAK/STAT pathway [23]. IFN- $\beta$ has also been suggested to modulate microglial activity in multiple sclerosis and pathological neovascularization $[24,25]$. Since IFN- $\beta$ signaling was well represented within our GO analysis, we believe that IFN- $\beta$ is important to the microglial modulation that occurs following KA-induced seizures.
Pathway analysis reveals both metabolic and immune response processes are altered

Finally, we performed pathway analysis on the differential expression data set using the clusterProfiler enrichKEGG function (Fig. 4). Unsurprisingly, this analysis corroborated our GO analysis results in that metabolism was significantly enriched in our data set. We also identified several pathways relating to neurological diseases (i.e., Parkinson's, Alzheimer's, and Huntington's disease) (Fig. 4). Using KEGGmapper we were able to further investigate which specific metabolic pathway were being affected. We found that Glycan, fatty acid and lipid, and nucleotide metabolism are all up-regulated within the KA treated samples. Moreover, we observed several pathways involving glutamate utilization and isoprenoid biosynthesis were also affected (Fig. 5a).

While metabolism was by far the most significantly altered pathway term identified, several other pathways of note were identified, specifically those relating to neurodegenerative diseases (i.e., Parkinson's, Huntington's, Alzheimer's) and viral response (i.e., Herpes simplex, Epstein-Barr, viral carcinogenesis). While it was consistent with our exploration avenue to observe pathways relating to neurodegenerative diseases, we observed viral responses in both $\mathrm{GO}$ and pathway analysis. As such, we further explored the gene relationships underlying these 


\section{a Cellular Component}

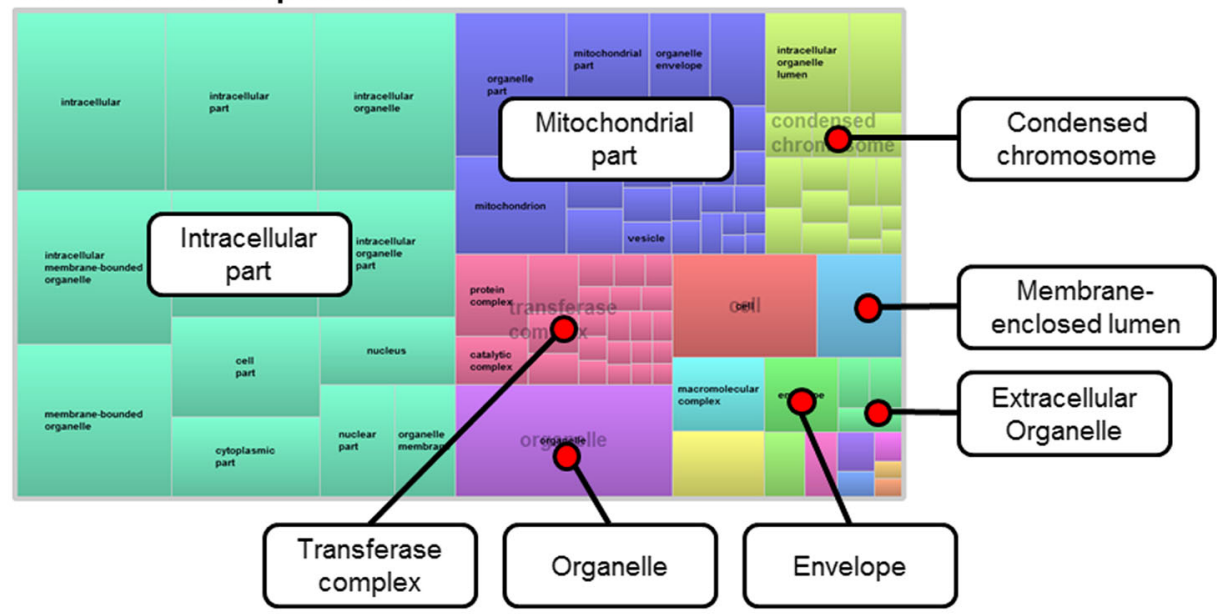

b Biological Process

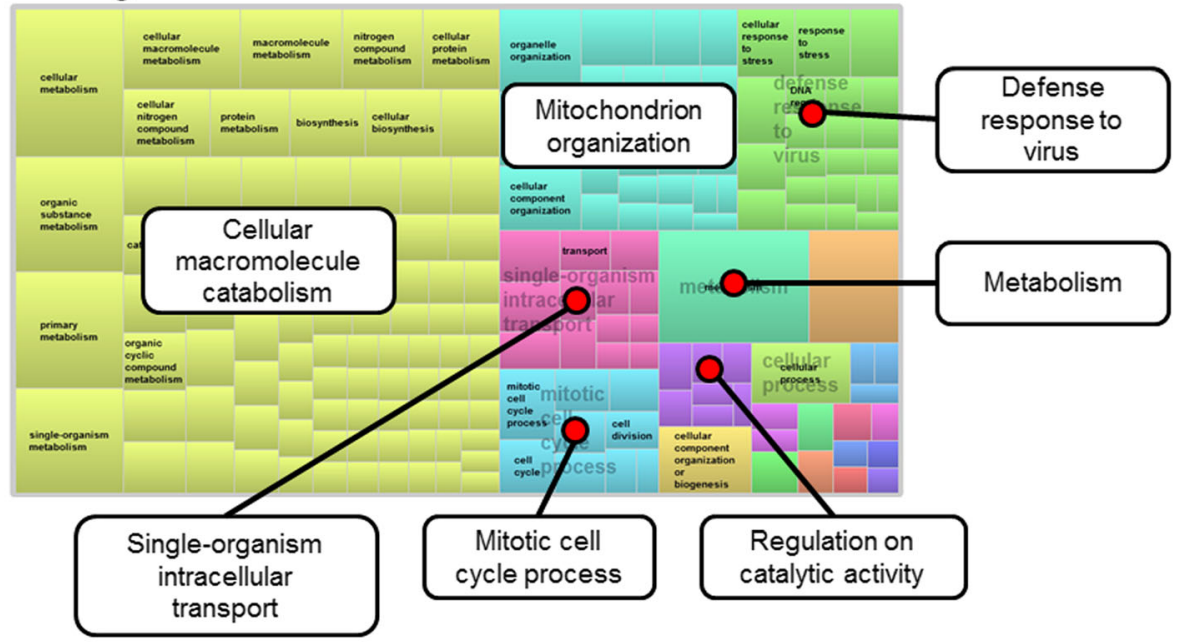

c Molecular Function

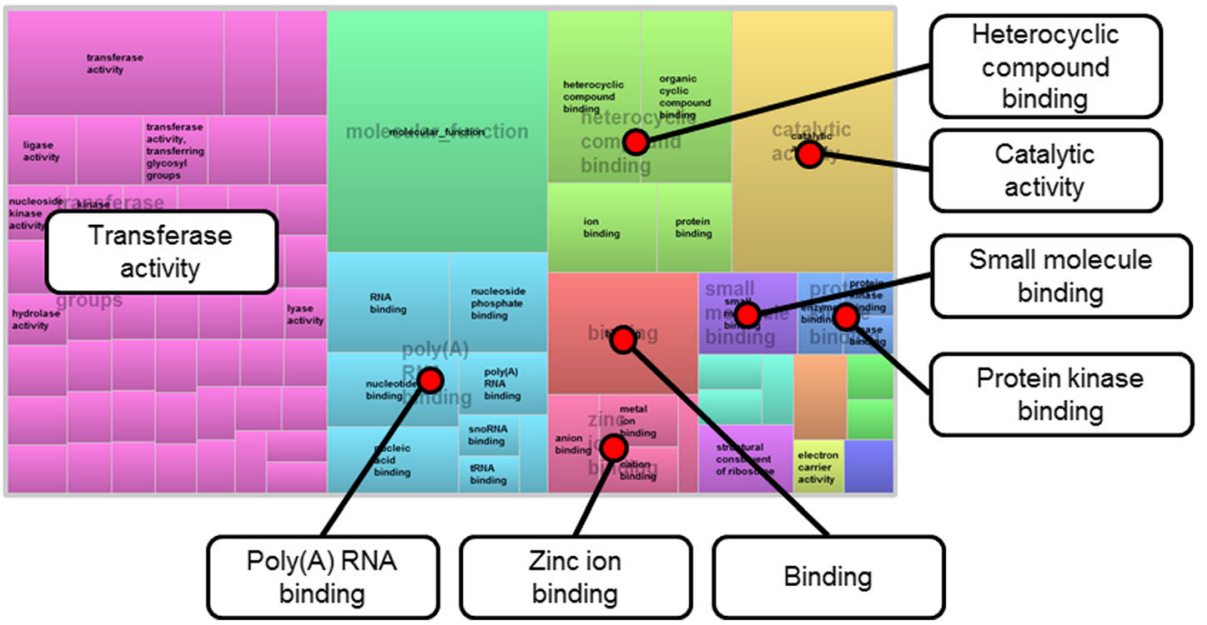

Fig. 3 (See legend on next page.) 
(See figure on previous page.)

Fig. 3 Functional classification of the differentially expressed genes. a Cellular component. b Biological process. c Molecular function. Visualization of identified Gene Ontology terms was completed using REViGO [22]. Analysis was run using the $P_{\text {adj }}$ for each identified term, medium allowed

similarity (0.7), and SimRel similarity measurement. Individual term size weight within each TreeMap was determined by associated $P_{\text {adj. }}$.

identified pathway terms. Differential expressed genes identified to be part of the indicated KEGG pathway terms were analyzed with the GeneMANIA application for Cytoscape V3.5.1 [26]. GeneMANIA utilizes both published information and computational predictions to identify relationships between input genes. It will also suggest possible interaction partners not initially input into the query. Indeed, we demonstrate that the overwhelming majority of genes associated with the identified neurodegenerative pathways were related to mitochondrial function, specifically the electron transport chain (Fig. 5b). This is consistent with our GO analysis. Investigation of viral pathway term genes however revealed a more diverse set of groupings (Fig. 5c). These include genes related to RNA polymerase complexes and histones. Both of which are consistent with the high levels of transcriptional modulation observed. Additionally, several genes were associated with immunological regulation, such as complement $\mathrm{C} 3$, signal transducer and activator of transcription 2 (Stat2), and antigen peptide transporter 1 (Tap1).

\section{Discussion}

The majority of research into epilepsy has focused on neuronal hyperactivities and cell death. However, the role of glia, particularly microglia, in the pathogenesis

Table 4 Type I interferon related GO terms

\begin{tabular}{lll}
\hline GO Term ID & Term Name & $P_{\text {adj }}$ \\
\hline GO:0032480 & $\begin{array}{l}\text { negative regulation of type I interferon } \\
\text { production }\end{array}$ & 0.0012 \\
GO:0032479 & regulation of type I interferon production & 0.0019 \\
GO:0034340 & response to type I interferon & 0.0046 \\
GO:0032606 & type I interferon production & 0.0055 \\
GO:0032648 & regulation of interferon-beta production & 0.0109 \\
GO:0032608 & interferon-beta production & 0.0166 \\
GO:0035456 & response to interferon-beta & 0.0173 \\
GO:0060337 & type I interferon signaling pathway & 0.0204 \\
GO:0071357 & cellular response to type I interferon & 0.0204 \\
GO:0032688 & $\begin{array}{l}\text { negative regulation of interferon-beta } \\
\text { production }\end{array}$ & 0.0375 \\
GO:0060340 & $\begin{array}{l}\text { positive regulation of type I interferon- } \\
\text { mediated signaling pathway }\end{array}$ & 0.0375 \\
GO:0035458 & cellular response to interferon-beta & 0.0429 \\
GO:0060338 & $\begin{array}{l}\text { regulation of type I interferon-mediated } \\
\text { signaling pathway }\end{array}$ & 0.0497 \\
\hline
\end{tabular}

of epilepsy is an important emerging area of study. Specifically, the transcriptomic alterations of microglia following KA-induced seizure have not been well studied. In this regard, we utilized RNAseq analysis on isolated hippocampal microglia to investigate microglial response during the acute phase after seizure. In total, our results clearly demonstrate that microglia undergo significant alterations following KA-induced seizures, including up-regulation of several inflammatory factors and modulation of mitochondrial activity.

\section{Microglia may undergo oxidative stress response following KA-induced seizure}

The most obvious phenotypic alteration was mitochondrial activity in microglia after seizures. While it is possible that up-regulation of mitochondrial genes is merely indicative of microglia transitioning from a resting to active state, it is also possible that microglia are increasing production of mitochondria-derived reactive oxygen species (ROS). While NADPH oxidase has often been described as the primary source of ROS, it has been well established that NADH dehydrogenase (electron transport chain complex I) can also contribute to ROS formation [27]. Indeed, several complex I subunits (e.g., Ndufs8, Ndufa5, Ndufb8) were differentially expressed in our dataset but no NADPH oxidase subunits were up-regulated. This idea is also supported by the observed up-regulation of superoxide dismutase (Sod) 1 and 2, both of which can convert the superoxide generated by the electron transport chain into hydrogen peroxide [28]. Sod 1 and 2 are critically important for the mitigation of oxidative stress and are altered during epilepsy.

When considering our other results, specifically the observed utilization of glutamate, there is further indication that microglia are responding to oxidative stressors. Our results identified two possible means by which glutamate could be utilized, conversion to either 1) proline or 2) glutathione. Of these, the generation of glutathione may be of significance. From our results we observed differential expression of glutathione peroxidase 3 (Gpx3), glutathione S-transferase omega 1 (Gsto1), glutathione transferase zeta 1 (Gstz1), and glutathione reductase (Gsr) expression, all of which are important to the mitigation of oxidative stress [29,30]. Understanding the consequence of this response could open new avenues into attenuating oxidative damage following seizures. Moreover, it is interesting that of the four main glutathione peroxidase variants, we only observed 


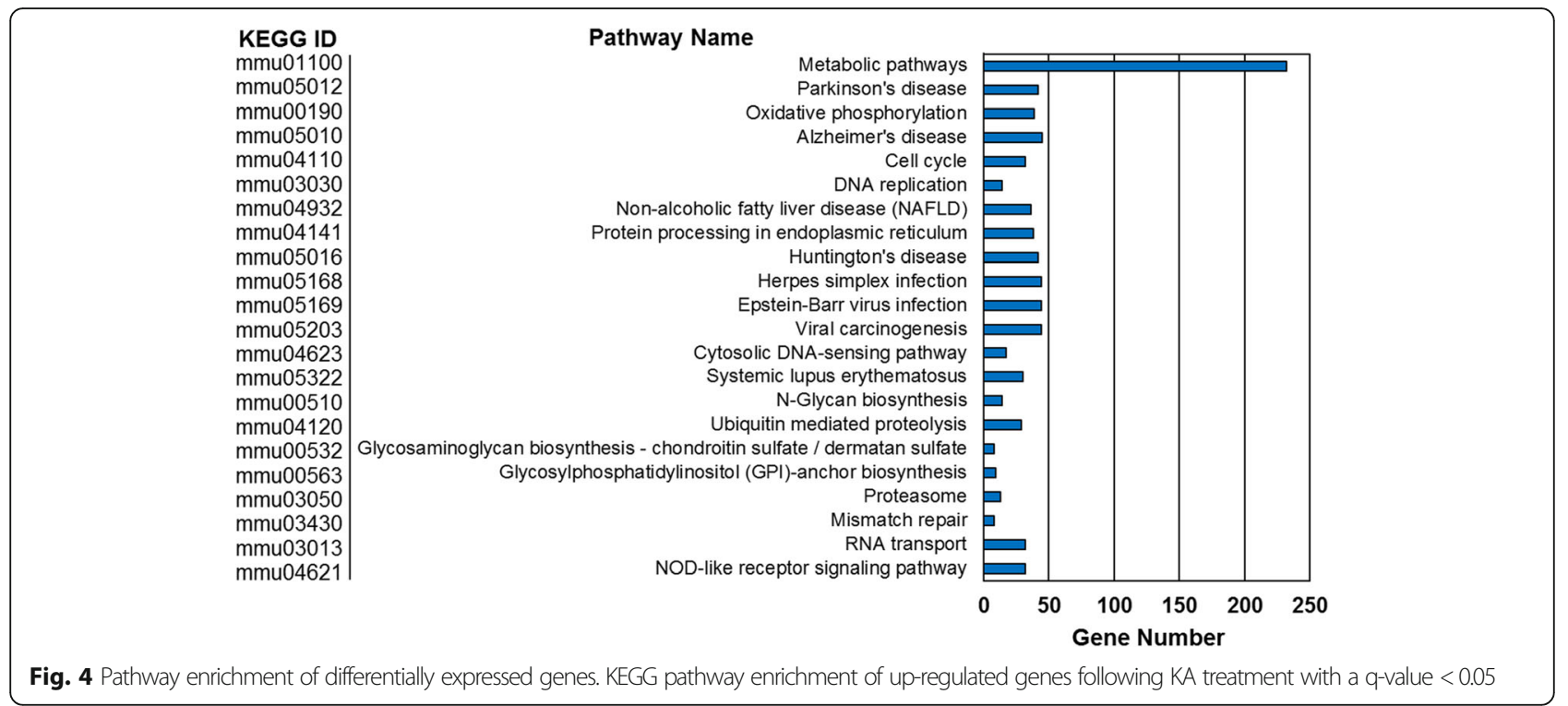

increases in Gpx3, which is found within the extracellular space [31]. It is possible that microglia are attempting to mitigate not only their own endogenous oxidative stress but also that within the environment.

\section{Microglia increase metabolic activity in response to KA-induced seizure}

Our results also showed that many genes relating to metabolic activity are significantly up-regulated. Specifically, GO and pathway analysis determined that microglia up-regulated lipid, nucleotide, and glycan metabolism. These metabolic activities have also been observed during transcriptional analysis of total rat cortex following sarin-induced seizure [32]. We also identified that geranylgeranyl diphosphate synthase 1 (Ggps1) was up-regulated. Ggps1 is responsible for synthesis of the isoprenoid intermediate geranylgeranyl diphosphate (GGPP), which can be attached to a wide assortment of proteins via geranylgeranyltransferases (GGT) like Rab GGT, whose alpha subunit was differentially expressed in our data set [33, 34]. Within Alzheimer's disease it was shown that GGPP may influence microglial inflammatory response via modulation of Rho GTPase [35]. Moreover, many of the positive effects of statin drugs (e.g., reducing excitotoxicity and inflammation) within Alzheimer's disease, Parkinson's disease, and multiple sclerosis could be attributed to mitigation of isoprenoid intermediates, like GGPP [36-39]. The observed mitigation of KA induced seizure symptoms by statins may also involve similar mechanisms [40]. Given our results, it would be of interest to determine if statins improve seizure recovery by attenuating microglial inflammatory response.
Microglia undergo immunological activation in response to KA-induced seizure

Microglia as a principal immune cell in the brain are activated in human epileptic brain and rodent seizure models [4]. Not surprisingly, we also observed that microglia underwent immunological activation, as seen by enrichment of viral response pathways, at 3 days post KA-induced seizures in mice. However, underlying each of these pathways was a shared set of up-regulated genes, including a number of histocompatibility genes, many of which seem to correlate with non-classical major histocompatibility complexes. More specifically, we observed that H2-T23, which encodes Qa-1, and several genes that make up Qa-2 (i.e., H2-Q6, H2-Q7, and H2-Q8) were differentially expressed within our data set $[41,42]$. These histocompatibility complexes have been shown to modulate the activity of natural killer (NK) cells $[43,44]$. In regards to neuroinflammation, it was reported that the soluble forms of MHC-E and MHC-G might be related to inflammation protection within multiple sclerosis [45]. However, very little has been done to investigate the roles of these histocompatibility complexes within epilepsy. Given the indications that NK cells are increased following temporal lobe epilepsy, it is worth investigating whether microglia are modulating NK cell activity within the hippocampal region following seizure induction, and whether this modulation is inhibitory of stimulatory.

\section{Interferon beta may modulate microglial activity following $K A$-induced seizure}

Another sign of microglial immunomodulation was the identification of a number of IFN- $\beta$ responsive terms during GO analysis. IFN- $\beta$ is typically seen as being 


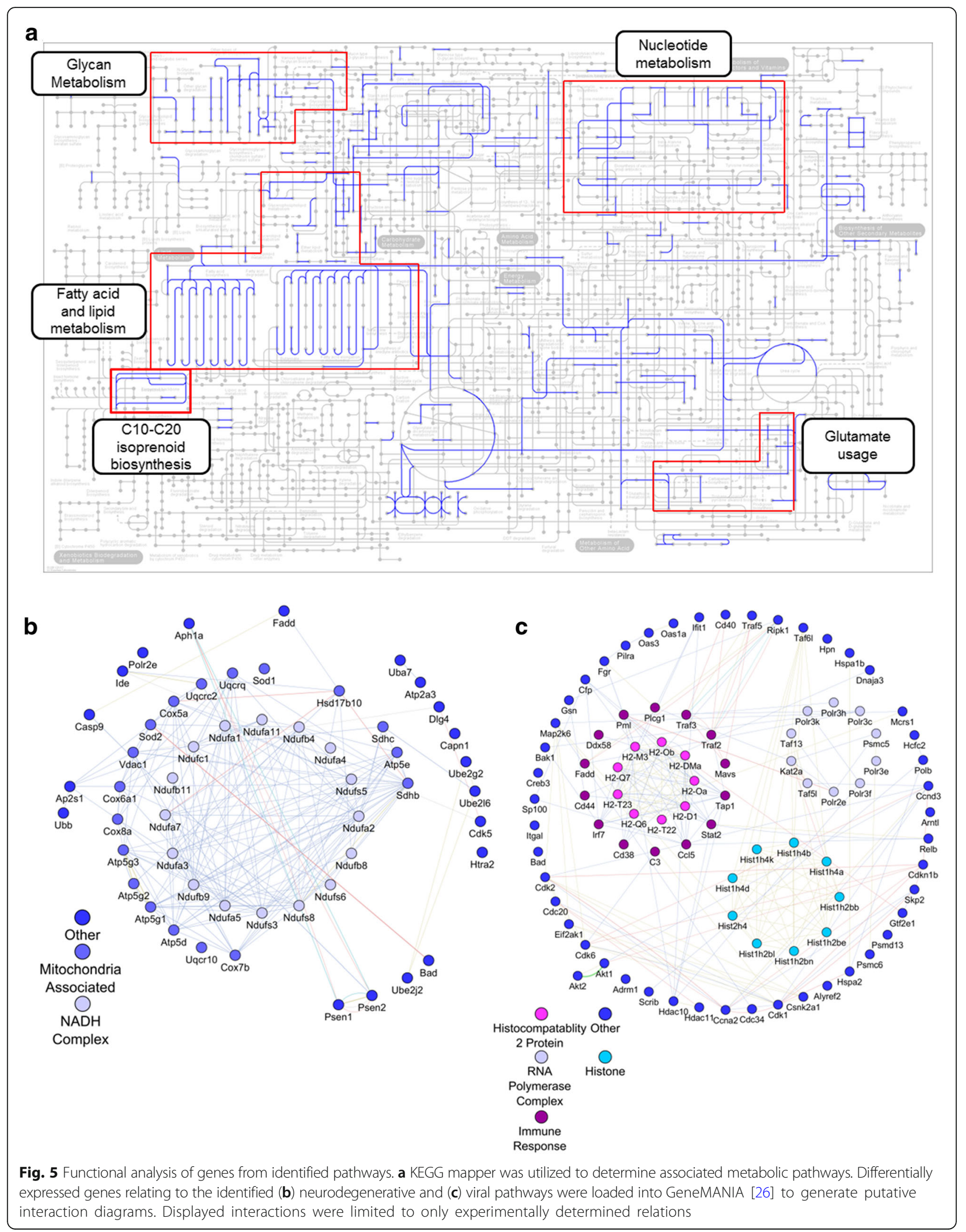


anti-inflammatory and has become a common treatment option for relapsing-remitting multiple sclerosis patients [46]. However, there are also indications that type-I interferons may negatively regulate brain activity during aging [47]. Thus, IFN- $\beta$ may have differential roles depending on disease context. In relation to microglia it has been shown that IFN- $\beta$ can induce chemokine CCL5 expression, which was highly up-regulated in our data set and in our recent cytokine array [15] after KA-induced seizures. It has also been shown that interferon regulatory factor 7 (Irf7), which is suggested to be the master regulator of type-I interferon-dependent immune response, can modulate CCL5 expression [48]. We observed that Irf7 was differently expressed following KA treatment, indicating a possible means by which IFN- $\beta$ could modulate microglia inflammatory responses following seizures. As a final note, it has been shown that some Irf7 activity may be tightly regulated by non-degenerative ubiquitination $[49,50]$. One of the most up-regulated genes in our data set following seizure was ubiquitin (Ubb). Consequently, our data set indicates that several facets of gene regulation are at play within microglia following KA treatment.

\section{Identified differentially expressed genes warranting further investigation}

Finally, while over 2300 differentially expressed genes were identified, we believe that the following selection may be of interest for further investigation. First is osteopontin (secreted phosphoprotein 1; Spp1), which has been observed within neuronal injuries, particularly ischemic stroke [51, 52]. However, little is known about how Spp1 is involved in epileptic seizures even though other less targeted profiling analyses have also noted its up-regulation following seizures $[53,54]$. What is known is that its expression seems to be localized to certain areas of the brain, including the CA1 and CA3 regions of the hippocampus $[55,56]$. Moreover, it has been suggested that only a sub-set of microglia actively express Spp1, with a possible role in phagocytosis [55]. However, the exact role of Spp1 following epilepsy requires further evaluation.

Next is the adenosine $A_{3}$ receptor (Adora3/A3ar). This gene is of interest as it was the only receptor to be down-regulated within our data set. Adenosine has long been viewed as an endogenous anticonvulsive and will increase dramatically during epileptic seizures [57]. As for Adora3, it was reported that its specific agonist, IB-MECA, could protect against seizures [58]. It was found that Adora3 is highly expressed in microglia and that LPS treatment down-regulates its expression [59]. Moreover, externally induced activation of Adora3 could reduce LPS-induced tumor necrosis factor alpha (TNF $\alpha$ ) in both RAW 264.7 macrophages and BV2 microglia
$[60,61]$. Yet, little else is known about how Adora3 can modulate microglial activity, let alone why we observed a significant down-regulation in expression following KA-induced seizure.

Lastly, while several purinergic receptors have been shown to modulate microglial function during epilepsy, including P2ry12 and P2rx7, we only observed significantly increased expression of P2rx4 [12]. This receptor has been observed to be important to the pathogenesis of several neurological conditions including neuropathic pain and epilepsy $[62,63]$. In regards to microglia, P2rx4 expression can be up-regulated via fibronectin, which was differentially expressed in our data set [64]. Within models of neuropathic pain, it has been suggested that activation of P2rx4 induced microglia to release brain-derived neurotropic factors (BDNF), which then affected neuronal activity by modulating GABAergic activity $[65,66]$. Since the hippocampus has a significant population of GABAergic interneurons, particularly in the CA1 and CA3 regions, it may be of interest to determine to what extent this crosstalk exists and whether or not blockage of this communication could alleviate seizure symptoms [67].

In conclusion, our results demonstrate that KA-induced seizure acutely affects the phenotypic character of microglia within the hippocampus. Specifically, microglia seem to be undergoing a variety of activations, which could potentially regulate neuronal hyperactivities and seizure behaviors. We have identified a number of mechanisms and gene targets that could provide future directions for therapeutic intervention.

\section{Methods \\ Mice}

The described In vivo procedures were approved by Institutional Animal Care and Use Committee (IACUC) in both Rutgers University and Mayo Clinic. We followed the guidelines set forth by the Guide of the Care and Use of Laboratory Animals 8th Edition. Both male and female adult heterozygous microglia GFP reporter mice at two months of age were used. The mice express GFP under control of the fractalkine receptor promo$\operatorname{ter}\left(\mathrm{CX} 3 \mathrm{CR} 1^{\mathrm{GFP} /+}\right)$ that selectively label microglia in the CNS [68].

\section{KA administration}

An injection of kainic acid (KA) (Tocris Biosciences, Bristol, UK) via direct intracerebroventricular (ICV) injection to induce seizure was performed as previously described [12, 15]. Briefly, a guide tube (24 gauge) was implanted into $\mathrm{CX} 3 \mathrm{CR} 1^{+/ \mathrm{GFP}}$ mice prior to KA injection. After a $24 \mathrm{~h}$ recovery period, a 30 gauge needle was inserted through the cannula to deliver the KA solution 
$(0.2 \mu \mathrm{g}$ in $5 \mu \mathrm{l})$. Mice were then observed for induction of seizure response using the method described previously [12]. Briefly, seizure behavior was monitored under a modified Racine scale as follows [12, 15, 69]:

(1) freezing behavior; (2) rigid posture with raised tail;

(3) continuous head bobbing and forepaws shaking;

(4) rearing, falling, and jumping; (5) continuous level 4; and (6) loss of posture and generalized convulsion activity. Mice progressed at least to stage 3 and were sacrificed 3d after seizure. Sham controls did not receive KA administration.

\section{Microglia isolation}

All mice were perfused with ice cold PBS (pH 7.4) 3 days post KA treatment. Hippocampi were excised, minced on ice, and suspended in a trypsin/EDTA solution for 20 mins, in a $37^{\circ} \mathrm{C}$ shaker. After incubation, $3 \mathrm{ml}$ DMEM and 50ul DNase was added to the cell suspension. Cell pellets where then suspended in $5 \mathrm{ml}$ HEPES (4-(2hydroxyethyl)-1- piperazineethanesulfonic acid) buffer, then centrifuged again. Pellets were finally re-suspended in $800 \mathrm{ml}$ HEPES buffer and transferred into a sorting tube on ice. GFP-labeled microglia were isolated via FACS on a MoFlo XDP Cell Sorter (Beckman Coulter, CA, USA). Microglia from sham controls were isolated in the same manner after a corresponding length of time.

\section{RNAseq analysis}

RNA was isolated with the RNeasy Plus Micro Kit (Qiagen, Hilden, Germany). RNA quality was evaluated by Tapestation RNA HS Assay (Agilent Technologies, CA, USA) and Bioanalyzer 2100 Eukaryote Total RNA Nano Kit (Agilent Technologies). Libraries were constructed with the SMART-Seq v4 Ultra Low Input RNA Kit (Takara-Clontech, CA, USA) using manufacturer's instructions. Final library quantity was determined by KAPA SYBR ${ }^{\circ}$ FAST qPCR and library quality evaluated by Tapestation RNA HS Assay (Agilent Technologies, CA, USA). Equimolar pooling of libraries were performed based on qPCR values and loaded onto an Illumina Hiseq platform (Illumina, CA, USA).

\section{Differential gene expression analysis}

RNA-seq data were aligned to the mouse reference genome using STAR mapping tool [70]. Read counts were then quantified using HTSeq-count [71]. DESeq, an R Bioconductor package, was used for differential gene expression analysis [72]. It estimates variance-mean dependence in RNA-seq count data and tests for differential expression using a negative binomial distribution model. Heat map and hierarchical clustering of differentially expressed genes was performed using the heatmap function in stats package in R.
Functional classification of differentially expressed genes Gene Ontology (GO) analysis is a commonly used approach for functional studies of RNA-seq data. To functional classify the differentially expressed genes between the control and KA treated groups, GO enrichment analysis using clusterProfiler was performed. Additionally, significant KEGG pathways were identified using the enrichKEGG function in clusterProfiler package with FDR $<0.05$.

\section{Statistics}

Both KA-treated and control were collected with $n=$ 3 mice. The $\mathrm{R}$ package DESeq was used on our RNAseq counts to estimate the variance-mean dependence and to test for differential expression. Differentially expressed proteins with adjusted $p$-values $<0.05$ using the Benjamini-Hochberg procedure. These proteins were then subjected to pathway enrichment/gene ontology analysis. A Benjamini-Hochberg adjusted $p$-value of $<0.05$ was used to identify significantly enriched pathways.

\section{Additional files}

\begin{abstract}
Additional file 1: Table S1. List of all identified differentially expressed genes. (XLSX $336 \mathrm{~kb}$ )

Additional file 2: Figure S1. Expression profiles of microglia specific markers. The expression of microglia specific markers, as determined by Hickman et al. [16] was investigated. The $\log _{2}$ base mean expression of each condition is presented for each gene. Presented error bars are standard error using the $\log _{2}$ standard deviation of each mean. ${ }^{*} P_{\text {adj }}<0.05$. Figure S2. Expression profiles of cytokine markers. The expression of a variety of cytokines was investigated. The $\log _{2}$ base mean expression of each condition is presented for each gene. Presented error bars are standard error using the $\log _{2}$ standard deviation of each mean. ${ }^{*} \mathrm{P}_{\text {adj }}<0.05$. (PDF $114 \mathrm{~kb}$ )
\end{abstract}

Additional file 3: Table S2. List of all identified biological process GO terms. (XLSX $44 \mathrm{~kb}$ )

Additional file 4: Table S3. List of all identifed molecular function GO terms. (XLSX $23 \mathrm{~kb}$ )

Additional file 5: Table S4. List of all identifed cellular

compartment GO terms. (XLSX 24 kb)

\section{Acknowledgements}

The authors would like to thank all members of Wu lab at Mayo for the insightful discussions and Dr. Paul A. Stewart (The Moffitt Cancer Center, Tampa, FL) for the technical assistance.

\section{Funding}

This work was supported by National Institute of Health (R01NS088627, R21DE025689, K22NS104392), and National Natural Science Foundation of China (No. 31500845)

Availability of data and materials

The datasets supporting the conclusion of this article are included within article.

Authors' contributions

$D B, J R R, W H$ and $W L J$ designed the study and wrote the manuscript; $D B, J Z$, JP, and LF generated mouse seizure model; JZ, ZX, JP, UBE, LF, GW performed the cell sorting experiments; KT, CY and JH performed RNAseq and data analysis; DB and WLJ analyzed the data and revised the manuscript. All authors read and approved the final manuscript. 


\section{Ethics approval}

All the animal-related procedures were conducted in accordance with the guidelines of the Institutional Animal Care and Use Committee of in both Rutgers University and Mayo Clinic and were consistent with the ethical guidelines of the National Institutes of Health. All efforts were made to minimize animal suffering and to reduce the number of animals used.

\section{Competing interests}

The authors declare that they have no competing interests.

\section{Publisher's Note}

Springer Nature remains neutral with regard to jurisdictional claims in published maps and institutional affiliations.

\section{Author details}

'Department of Neurology, Mayo Clinic, 200 First Street SW, Rochester, MN 55905, USA. ${ }^{2}$ Department of Pharmacology, School of Pharmacy, Nantong University, 19 Qixiu Road, Nantong 226001, Jiangsu, China. ${ }^{3}$ Admera Health LLC, South Plainfield, NJ 07080, USA. ${ }^{4}$ Department of Histology and Embryology, School of Basic Medical Sciences, Anhui Medical University, Hefei 230032, Anhui, China. ${ }^{5}$ One Harvard Street Institute of Health, Brookline, MA 02446, USA. ${ }^{6}$ Department of Pharmaceutical Sciences and Center for Neurodegenerative Disease and Aging, Northeast Ohio Medical University, Rootstown, $\mathrm{OH} 44272$, USA. ${ }^{7}$ Department of Neuroscience and Cell Biology, Rutgers-Robert Wood Johnson Medical School, Piscataway, NJ 08854, USA. ${ }^{8}$ Department of Neuroscience, Mayo Clinic, Jacksonville, FL 32224, USA.

\section{Received: 29 April 2018 Accepted: 28 May 2018}

\section{Published online: 20 June 2018}

\section{References}

1. Kwan P, Brodie MJ. Clinical trials of antiepileptic medications in newly diagnosed patients with epilepsy. Neurology. 2003;60(11 Suppl 4):S2-12.

2. Levesque $M$, Avoli M. The kainic acid model of temporal lobe epilepsy. Neurosci Biobehav Rev. 2013:37(10 Pt 2):2887-99.

3. Wilcox KS, Gee JM, Gibbons MB, Tvrdik P, White JA. Altered structure and function of astrocytes following status epilepticus. Epilepsy Behav. 2015;49:17-9.

4. Eyo UB, Murugan M, Wu L. Microglia-neuron communication in epilepsy. Glia. 2017:65(1):5-18.

5. Eyo UB, Wu L. Bi-directional microglia-neuron communication in the healthy brain. Neural Plast. 2013;2013:456857.

6. Parkhurst CN, Yang G, Ninan I, Savas JN, Yates JR 3rd, Lafaille JJ, Hempstead BL, Littman DR, Gan WB. Microglia promote learning-dependent synapse formation through brain-derived neurotrophic factor. Cell. 2013;155(7):1596-609.

7. Beach TG, Woodhurst WB, MacDonald DB, Jones MW. Reactive microglia in hippocampal sclerosis associated with human temporal lobe epilepsy. Neurosci Lett. 1995;191(1-2):27-30.

8. Wyatt-Johnson SK, Herr SA, Brewster AL. Status epilepticus triggers timedependent alterations in microglia abundance and morphological phenotypes in the Hippocampus. Front Neurol. 2017:8:700.

9. Eyo UB, Gu N, De S, Dong H, Richardson JR, Wu LJ. Modulation of microglial process convergence toward neuronal dendrites by extracellular calcium. J Neurosci. 2015;35(6):2417-22.

10. Eyo UB, Mo M, Yi MH, Murugan M, Liu J, Yarlagadda R, Margolis DJ, Xu P, Wu LJ. P2Y12R-dependent translocation mechanisms gate the changing microglial landscape. Cell Rep. 2018;23(4):959-66.

11. Eyo UB, Peng J, Murugan M, Mo M, Lalani A, Xie P, Xu P, Margolis DJ, Wu LJ. Regulation of physical microglia-neuron interactions by Fractalkine signaling after status epilepticus. eNeuro. 2017;3(6)

12. Eyo UB, Peng J, Swiatkowski P, Mukherjee A, Bispo A, Wu LJ. Neuronal hyperactivity recruits microglial processes via neuronal NMDA receptors and microglial P2Y12 receptors after status epilepticus. J Neurosci. 2014; 34(32):10528-40.

13. Mika J. Modulation of microglia can attenuate neuropathic pain symptoms and enhance morphine effectiveness. Pharmacol Rep. 2008;60(3):297-307.

14. Bronen RA. The status of status: seizures are bad for your brain's health. AJNR Am J Neuroradiol. 2000;21(10):1782-3.

15. Tian DS, Peng J, Murugan M, Feng L, Liu JL, Eyo UB, Zhou LJ, Mogilevsky R, Wang W, Wu $\sqcup$. Chemokine CCL2-CCR2 signaling induces neuronal cell death via STAT3 activation and IL-1 beta production after status epilepticus. J Neurosci. 2017;37(33):7878-92.

16. Hickman SE, Kingery ND, Ohsumi TK, Borowsky ML, Wang LC, Means TK, El Khoury J. The microglial sensome revealed by direct RNA sequencing. Nat Neurosci. 2013;16(12):1896-905

17. Abiega O, Beccari S, Diaz-Aparicio I, Nadjar A, Laye S, Leyrolle Q, GomezNicola D, Domercq M, Perez-Samartin A, Sanchez-Zafra V, et al. Neuronal hyperactivity disturbs ATP microgradients, impairs microglial motility, and reduces phagocytic receptor expression triggering apoptosis/microglial phagocytosis uncoupling. PLoS Biol. 2016;14(5):e1002466.

18. Trias E, Díaz-Amarilla P, Olivera-Bravo S, Isasi E, Drechsel DA, Lopez N, Bradford CS, Ireton KE, Beckman JS, Barbeito L. Phenotypic transition of microglia into astrocyte-like cells associated with disease onset in a model of inherited ALS. Front Cell Neurosci. 2013;7:274.

19. Brown A. Understanding the MIND phenotype: macrophage/microglia inflammation in neurocognitive disorders related to human immunodeficiency virus infection. Clin Translat Med. 2015;4:7.

20. Louveau A, Nerriere-Daguin V, Vanhove B, Naveilhan P, Neunlist M, Nicot A, Boudin $\mathrm{H}$. Targeting the CD80/CD86 costimulatory pathway with CTLA4-lg directs microglia toward a repair phenotype and promotes axonal outgrowth. Glia. 2015;63(12):2298-312.

21. Yu G, Wang LG, Han Y, He QY. clusterProfiler: an R package for comparing biological themes among gene clusters. Omics. 2012;16(5):284-7.

22. Supek F, Bosnjak M, Skunca N, Smuc T. REVIGO summarizes and visualizes long lists of gene ontology terms. PLoS One. 2011;6(7):e21800.

23. Schreiber $\mathrm{G}$, Piehler J. The molecular basis for functional plasticity in type interferon signaling. Trends Immunol. 2015;36(3):139-49.

24. Kawanokuchi J, Mizuno T, Kato H, Mitsuma N, Suzumura A. Effects of interferon-beta on microglial functions as inflammatory and antigen presenting cells in the central nervous system. Neuropharmacology. 2004;46(5):734-42.

25. Luckoff A, Caramoy A, Scholz R, Prinz M, Kalinke U, Langmann T. Interferonbeta signaling in retinal mononuclear phagocytes attenuates pathological neovascularization. EMBO Mol Med. 2016;8(6):670-8.

26. Montojo J, Zuberi K, Rodriguez H, Kazi F, Wright G, Donaldson SL, Morris Q, Bader GD. GeneMANIA Cytoscape plugin: fast gene function predictions on the desktop. Bioinformatics (Oxford, England). 2010;26(22):2927-8.

27. Murphy MP. How mitochondria produce reactive oxygen species. Biochem J. 2009;417(1):1-13.

28. Dan Dunn J, Alvarez LA, Zhang X, Soldati T. Reactive oxygen species and mitochondria: a nexus of cellular homeostasis. Redox Biol. 2015;6:472-85.

29. Allen M, Zou F, Chai HS, Younkin CS, Miles R, Nair AA, Crook JE, Pankratz VS, Carrasquillo MM, Rowley CN, et al. Glutathione S-transferase omega genes in Alzheimer and Parkinson disease risk, age-at-diagnosis and brain gene expression: an association study with mechanistic implications. Mol Neurodegener. 2012;7:13.

30. Couto N, Wood J, Barber J. The role of glutathione reductase and related enzymes on cellular redox homoeostasis network. Free Radic Biol Med. 2016;95:27-42.

31. Olson GE, Whitin JC, Hill KE, Winfrey VP, Motley AK, Austin LM, Deal J, Cohen HJ, Burk RF. Extracellular glutathione peroxidase (Gpx3) binds specifically to basement membranes of mouse renal cortex tubule cells. Am J Physiol Renal Physiol. 2010;298(5):F1244-53.

32. Spradling KD, Lumley LA, Robison CL, Meyerhoff JL, Dillman JF 3rd. Transcriptional analysis of rat piriform cortex following exposure to the organophosphonate anticholinesterase sarin and induction of seizures. J Neuroinflammation. 2011;8:83.

33. Maurer-Stroh S, Washietl S, Eisenhaber F. Protein prenyltransferases. Genome Biol. 2003;4(4):212.

34. Wiemer AJ, Hohl RJ, Wiemer DF. The intermediate enzymes of isoprenoid metabolism as anticancer targets. Anti Cancer Agents Med Chem. 2009;9(5): 526-42.

35. Cordle A, Landreth G. 3-Hydroxy-3-methylglutaryl-coenzyme a reductase inhibitors attenuate beta-amyloid-induced microglial inflammatory responses. J Neurosci. 2005;25(2):299-307.

36. Kuipers HF, van den Elsen PJ. Immunomodulation by statins: inhibition of cholesterol vs. isoprenoid biosynthesis. Biomed Pharmacother. 2007;61(7): 400-7.

37. Li L, Zhang W, Cheng S, Cao D, Parent M. Isoprenoids and related pharmacological interventions: potential application in Alzheimer's disease. Mol Neurobiol. 2012;46(1):64-77.

38. Wahner AD, Bronstein JM, Bordelon YM, Ritz B. Statin use and the risk of Parkinson disease. Neurology. 2008;70(16 Pt 2):1418-22. 
39. Roy A, Pahan K. Prospects of statins in Parkinson disease. Neuroscientist. 2011;17(3):244-55.

40. Lee JK, Won JS, Singh AK, Singh I. Statin inhibits kainic acid-induced seizure and associated inflammation and hippocampal cell death. Neurosci Lett. 2008:440(3):260-4.

41. Lo WF, Woods AS, DeCloux A, Cotter RJ, Metcalf ES, Soloski MJ. Molecular mimicry mediated by MHC class $\mathrm{Ib}$ molecules after infection with gramnegative pathogens. Nat Med. 2000;6(2):215-8.

42. Cai W, Cao W, Wu L, Exley GE, Waneck GL, Karger BL, Warner CM. Sequence and transcription of Qa-2-encoding genes in mouse lymphocytes and blastocysts. Immunogenetics. 1996;45(2):97-107.

43. Chiang EY, Henson M, Stroynowski I. The nonclassical major histocompatibility complex molecule Qa-2 protects tumor cells from NK cell- and lymphokineactivated killer cell-mediated cytolysis. J Immunol. 2002;168(5):2200-11.

44. Gays F, Fraser KP, Toomey JA, Diamond AG, Millrain MM, Dyson PJ, Brooks CG. Functional analysis of the molecular factors controlling Qa1-mediated protection of target cells from NK lysis. J Immunol. 2001;166(3):1601-10.

45. Morandi F, Venturi C, Rizzo R, Castellazzi M, Baldi E, Caniatti ML, Tola MR, Granieri E, Fainardi E, Uccelli A, et al. Intrathecal soluble HLA-E correlates with disease activity in patients with multiple sclerosis and may cooperate with soluble HLA-G in the resolution of neuroinflammation. J Neuroimmune Pharmacol. 2013;8(4):944-55.

46. Limmroth $\mathrm{V}$, Putzki N, Kachuck NJ. The interferon beta therapies for treatment of relapsing-remitting multiple sclerosis: are they equally efficacious? A comparative review of open-label studies evaluating the efficacy, safety, or dosing of different interferon beta formulations alone or in combination. Ther Adv Neurol Disord. 2011;4(5):281-96.

47. Baruch K, Deczkowska A, David E, Castellano JM, Miller O, Kertser A, Berkutzki T, Barnett-Itzhaki Z, Bezalel D, Wyss-Coray T, et al. Aging. Aging-induced type I interferon response at the choroid plexus negatively affects brain function. Science (New York, NY). 2014;346(6205):89-93.

48. Honda K, Yanai H, Negishi H, Asagiri M, Sato M, Mizutani T, Shimada N, Ohba Y, Takaoka A, Yoshida N, et al. IRF-7 is the master regulator of type-I interferon-dependent immune responses. Nature. 2005;434(7034):772-7.

49. Huye LE, Ning S, Kelliher M, Pagano JS. Interferon regulatory factor 7 is activated by a viral oncoprotein through RIP-dependent ubiquitination. Mol Cell Biol. 2007;27(8):2910-8.

50. Ning S, Campos AD, Darnay BG, Bentz GL, Pagano JS. TRAF6 and the three C-terminal lysine sites on IRF7 are required for its ubiquitination-mediated activation by the tumor necrosis factor receptor family member latent membrane protein 1. Mol Cell Biol. 2008;28(20):6536-46.

51. Gliem M, Krammes K, Liaw L, van Rooijen N, Hartung HP, Jander S. Macrophage-derived osteopontin induces reactive astrocyte polarization and promotes re-establishment of the blood brain barrier after ischemic stroke. Glia. 2015;63(12):2198-207.

52. Chiu IM, Morimoto ETA, Goodarzi H, Liao JT, O'Keeffe S, Phatnani HP, Muratet M, Carroll MC, Levy S, Tavazoie S, et al. A neurodegeneration-specific gene expression signature and immune profile of acutely isolated microglia from an ALS mouse model. Cell Rep. 2013;4(2):385-401.

53. Hunsberger JG, Bennett AH, Selvanayagam E, Duman RS, Newton SS. Gene profiling the response to kainic acid induced seizures. Brain Res Mol Brain Res. 2005;141(1):95-112.

54. Gorter JA, van Vliet EA, Aronica E, Breit T, Rauwerda H, Lopes da Silva FH, Wadman WJ. Potential new antiepileptogenic targets indicated by microarray analysis in a rat model for temporal lobe epilepsy. J Neurosci. 2006; 26(43):11083-110.

55. Kim SY, Choi YS, Choi JS, Cha JH, Kim ON, Lee SB, Chung JW, Chun MH, Lee MY. Osteopontin in kainic acid-induced microglial reactions in the rat brain. Mol Cells. 2002:13(3):429-35.

56. Borges K, Gearing M, Rittling S, Sorensen ES, Kotloski R, Denhardt DT, Dingledine R. Characterization of osteopontin expression and function after status epilepticus. Epilepsia. 2008;49(10):1675-85.

57. Pedata F, Pugliese A, Sebastião A, Ribeiro J: Adenosine A3 receptor signaling in the central nervous system; 2010.

58. Von Lubitz DK, Carter MF, Deutsch SI, Lin RC, Mastropaolo J, Meshulam Y, Jacobson KA. The effects of adenosine A3 receptor stimulation on seizures in mice. Eur J Pharmacol. 1995;275(1):23-9.

59. Bennett ML, Bennett FC, Liddelow SA, Ajami B, Zamanian JL, Fernhoff NB, Mulinyawe SB, Bohlen CJ, Adil A, Tucker A, et al. New tools for studying microglia in the mouse and human CNS. Proc Natl Acad Sci U S A. 2016; 113(12):E1738-46.
60. Martin L, Pingle SC, Hallam DM, Rybak LP, Ramkumar V. Activation of the adenosine A3 receptor in RAW 264.7 cells inhibits lipopolysaccharidestimulated tumor necrosis factor-alpha release by reducing calciumdependent activation of nuclear factor-kappaB and extracellular signal-regulated kinase 1/2. J Pharmacol Exp Ther. 2006;316(1):71-8.

61. Lee JY, Jhun BS, Oh YT, Lee JH, Choe W, Baik HH, Ha J, Yoon KS, Kim SS, Kang I. Activation of adenosine A3 receptor suppresses lipopolysaccharideinduced TNF-alpha production through inhibition of PI 3-kinase/Akt and NF-kappaB activation in murine BV2 microglial cells. Neurosci Lett. 2006; 396(1):1-6.

62. Ulmann L, Levavasseur F, Avignone E, Peyroutou R, Hirbec H, Audinat E, Rassendren F. Involvement of P2X4 receptors in hippocampal microglial activation after status epilepticus. Glia. 2013;61(8):1306-19.

63. Ulmann L, Hatcher JP, Hughes JP, Chaumont S, Green PJ, Conquet F, Buell GN, Reeve AJ, Chessell IP, Rassendren F. Up-regulation of P2X4 receptors in spinal microglia after peripheral nerve injury mediates BDNF release and neuropathic pain. J Neurosci. 2008;28(44):11263-8.

64. Tsuda M, Toyomitsu E, Komatsu T, Masuda T, Kunifusa E, Nasu-Tada K, Koizumi S, Yamamoto K, Ando J, Inoue K. Fibronectin/integrin system is involved in P2X(4) receptor upregulation in the spinal cord and neuropathic pain after nerve injury. Glia. 2008;56(5):579-85.

65. Trang T, Beggs S, Wan X, Salter MW. P2X4-receptor-mediated synthesis and release of brain-derived neurotrophic factor in microglia is dependent on calcium and p38-mitogen-activated protein kinase activation. J Neurosci. 2009;29(11):3518-28.

66. Malcangio M. GABAB receptors and pain. Neuropharmacology. 2017. https://www.sciencedirect.com/science/article/pii/ S0028390817302186?via\%3Dihub.

67. Pelkey KA, Chittajallu R, Craig MT, Tricoire L, Wester JC, McBain CJ. Hippocampal GABAergic inhibitory interneurons. Physiol Rev. 2017;97(4):1619-747.

68. Jung S, Aliberti J, Graemmel P, Sunshine MJ, Kreutzberg GW, Sher A, Littman DR. Analysis of fractalkine receptor CX(3)CR1 function by targeted deletion and green fluorescent protein reporter gene insertion. Mol Cell Biol. 2000; 20(11):4106-14.

69. Racine RJ. Modification of seizure activity by electrical stimulation. II. Motor seizure. Electroencephalogr Clin Neurophysiol. 1972;32(3):281-94.

70. Dobin A, Davis CA, Schlesinger F, Drenkow J, Zaleski $C$, Jha $S$, Batut $P$, Chaisson M, Gingeras TR. STAR: ultrafast universal RNA-seq aligner. B ioinformatics (Oxford England). 2013;29(1):15-21.

71. Anders S, Pyl PT, Huber W. HTSeq-a Python framework to work with highthroughput sequencing data. Bioinformatics (Oxford England). 2015;31(2): 166-9.

72. Anders $\mathrm{S}$, Huber W. Differential expression analysis for sequence count data. Genome Biol. 2010;11(10):R106.

\section{Ready to submit your research? Choose BMC and benefit from:}

- fast, convenient online submission

- thorough peer review by experienced researchers in your field

- rapid publication on acceptance

- support for research data, including large and complex data types

- gold Open Access which fosters wider collaboration and increased citations

- maximum visibility for your research: over $100 \mathrm{M}$ website views per year

At BMC, research is always in progress.

Learn more biomedcentral.com/submissions 